\title{
PERSPECTIVAS SOBRE LA EDUCACIÓN MÉDICA EN AMÉRICA LATINA
}

\section{Perspectives on medical education in Latin America}

La medicina tiene un sitio privilegiado en la sociedad y por consiguiente la educación médica ocupa un lugar destacado en la educación superior, entre otras cosas, porque la medicina es quizás la única disciplina del conocimiento que tiene un sistema educativo propio que incluye el pregrado, el posgrado y la educación continuada o para toda la vida.

La definición de educación médica tiene varias acepciones, una de ellas, a nuestro juicio muy interesante, se refiere a que es "el proceso de formación de los médicos subordinado a las estructuras económicas y sociales dominantes en las sociedades en las que se lleva a cabo”, lo cual implica que no puede estar disociada de la realidad social, cultural e histórica. Esta definición encierra por sí sola, el gran cambio que hay que introducirle a la educación médica, en especial en países en vías de desarrollo.

En un reciente libro nuestro ${ }^{1}$, decíamos que las reformas a la enseñanza y el aprendizaje de la medicina, particularmente en el pregrado, continuaban basándose en una visión biologista del proceso salud-enfermedad y que en consecuencia era indispensable un cambio de paradigma. Lo primero para cambiar es el concepto del proceso salud-enfermedad que debe partir de que este es primariamente un proceso social y cultural dentro del cual se inserta lo biológico y psicológico. Lo anterior implica repensar para qué se enseña, sino es para que los educandos contribuyan a aumentar el bienestar de la población en la cual intervienen, de una manera integrada (bio, pisco-social, cultural e histórica). Lo segundo está relacionado con el cómo se aprende. Para ello el proceso educativo debería estar estructurado sobre la Enseñanza para la Comprensión (EpC), y no sobre la educación memorística. Comprender significa hacer cosas utilizando los conocimientos previos para resolver problemas en situaciones inéditas; en consecuencia, hay que dejar de estructurar el proceso educativo sobre el saber, que es conocer de muchas cosas, para focalizarlo en el comprender, que es poner todo en contexto porque los datos sueltos no sirven para nada. Y el tercer cambio se fundamenta en el cómo se enseña, basándose primordialmente en el diseño e implementación de un currículo basado en resultados de aprendizaje (learning outcomes), mal llamados competencias, que no es otra cosa que determinar lo que se espera que los estudiantes sepan, sean capaces de hacer y cómo deben comportarse una vez terminado el proceso de enseñanza-aprendizaje.

Adicional a lo anterior, es imprescindible incidir en la formación del médico de forma tal que éste sea capaz de trabajar como miembro de un equipo interdisciplinario que se comunica efectivamente, entendiendo la interdisciplinariedad como aquello que no se enfoca en temas sino en aspectos comunes entre distintas disciplinas, las cuales en el plan de estudios se emplean simultáneamente y no son fácilmente reconocibles dentro de un programa y en la práctica se traduce en interdependencia, que es la capacidad que tiene el individuo, mediante sus propios esfuerzos, de combinarlos, desarrollarlos o compartirlos con otros individuos con el fin de lograr el éxito, de manera recíproca; esta acción per se requiere de mucho esfuerzo, habida cuenta de la forma individualizada como los médicos hemos ejercido la medicina siempre.

Las reformas curriculares de los programa de medicina en nuestras naciones, para cumplir con esos cambios, se fundamentan, además, en unos requisitos esenciales en la formación médica, como los impulsados por el Instituto Internacional de Educación Médica (IIME por sus siglas en inglés), que incluyen siete categorías sobre las cuales debe construirse el currículo moderno. Las primeras tres: análisis crítico e investigación, manejo de la información, y habilidades de comunicación, se resumen, para nosotros, en lo que hemos denominado “nuevo trívium”, que no es otra cosa que el rescate de la gramática, la dialéctica y la lógica, que en algún momento de la educación superior quedaron olvidadas, pero adecuadas al momento actual a través del desarrollo de competencias cognitivo y lingüisticas, y de pensamiento lógico (matemático), que permitan que los estudiantes aprendan a leer bien, escribir bien, pensar bien y por ende comunicar bien, fundamento esencial de lo socio-humanístico: el arte de la medicina. 
Otra característica de los requisitos mínimos curriculares del IIME incluyen los valores profesionales, actitudinales y de comportamiento ético, para nosotros englobados dentro de lo que se denomina profesionalismo. Las otras tres categorias, tienen que ver con los fundamentos cientificos de la medicina, el desarrollo de habilidades clínicas y de competencias en salud pública y sistemas de salud. Lo que reconocemos como salud de poblaciones y atención primaria.

Es en este punto donde enfatizamos que el proceso de enseñanza y aprendizaje de la medicina no puede ser a espaldas del sistema de salud y que por lo tanto requiere de una renovación basada en la tercera generación de reformas curriculares en concordancia con Frenk y cols ${ }^{2}$. Para ellos, han existido tres generaciones de reformas curriculares en medicina. La primera, indudablemente, la introducida por Flexner; la segunda la utilización de una nueva forma de enseñar medicina: el Aprendizaje Basado en Problemas (ABP); la tercera, la educación médica basada en las necesidades del sistema de salud donde los profesionales van a ejercer de forma tal que sus desempeños favorezcan al mismo. Para Frenk y su grupo, la educación del siglo pasado fue inicialmente informativa, luego con los cambios y las modalidades educativas se transformó en una educación formativa y ahora, para este siglo, proponen que la educación sea transformativa, lo cual quiere decir que los profesionales de la salud, sean agentes de cambio capaces de transformar el sistema de salud para el cual ejercen, en el mejor interés de los pacientes.

Una educación médica transformativa, basada en las necesidades del sistema de salud, debe volver realidad el llamado mundial a incluir en ella la atención primaria, entendida esta como la promoción de la saludy la prevención de la enfermedad entrelazada con los siguientes niveles de atención, lo que hoy se conoce como atención primaria renovada, que incluya los ambientes comunitarios, lo cual se corresponde conceptualmente con lo expresado en la reunión de las Naciones Unidas en Alma Ata en 1978; ratificado por los ministros de salud de las américas en la Carta de Ottawa de 1986, y por la Conferencia Mundial de Educación Médica de Edimburgo en 1998 y subsecuentes, en relación con la necesidad de focalizar la atención en salud, y por ende la educación en salud, en la prevención y la promoción lo cual ha sido poco o nada implementada en los procesos de enseñanza-aprendizaje de nuestros profesionales de la salud.

En ese orden de ideas es que concordamos plenamente con la definición de educación médica expuesta anteriormente en cuanto a que ésta es, ciertamente, un proceso, que incluye el pregrado, el posgrado y la educación continuada o para toda la vida, y que debe estar subordinado a las estructuras económicas y sociales dominantes en las sociedades en las que se lleva a cabo, no a espaldas de éstas, y por consiguiente, no puede estar disociada de la realidad social, cultural e histórica de nuestras naciones y sus necesidades, pues para qué se enseña medicina sino es para que los médicos que surjan de dicho proceso incidan favorablemente en el bienestar de la sociedad donde les corresponda ejercer, como ocurrió con la reforma Flexner, que triplicó, en su momento, la expectativa de vida al nacer.

Gustavo A. Quintero, MD, MSc, FRCS. Profesor Titular de Cirugía Director de la Oficina de Reforma Curricular de Medicina Escuela de Medicina y Ciencias de la Salud Universidad del Rosario Bogotá, Colombia gustavo.quintero@urosario.edu.co

\section{Referencias}

1. Quintero GA. La formación del Médico. En: Quintero GA. Educación Médica. Diseño e implementación de un currículo basado en resultados del aprendizaje. Colección Pedagogía. Editorial Universidad del Rosario. 2012. pp. 117-33.
2. Frenk J, Chen L, Bhutta Z, Cohen J, Crisp N, Evans T, et al. Health Professionals for a New Century: transforming education to strengthen health systems in an independent world. The Lancet Commissions. Published on line Nov.29, 2010. DOI:10.1016/S0140-6736(10)61854-5. 